\title{
Diverticular disease: Epidemiology and management
}

\author{
Adam V Weizman MD, FRCPC ${ }^{1}$, Geoffrey C Nguyen MD PhD FRCPC 1,2
}

\author{
AV Weizman, GC Nguyen. Diverticular disease: Epidemiology \\ and management. Can J Gastroenterol 2011;25(7):385-389.
}

Diverticular disease of the colon is among the most prevalent conditions in western society and is among the leading reasons for outpatient visits and causes of hospitalization. While previously considered to be a disease primarily affecting the elderly, there is increasing incidence among individuals younger than 40 years of age. Diverticular disease most frequently presents as uncomplicated diverticulitis, and the cornerstone of management is antibiotic therapy and bowel rest. Segmental colitis associated with diverticula shares common histopathological features with inflammatory bowel disease and may benefit from treatment with 5 -aminosalicylates. Surgical management may be required for patients with recurrent diverticulitis or one of its complications including peridiverticular abscess, perforation, fistulizing disease, and strictures and/or obstruction.

Key Words: Acute diverticulitis; Diverticular disease; Epidemiology; Recurrent diverticulitis; Segmental colitis associated with diverticula $(\mathrm{SCAD})$

$\mathrm{D}$ iverticular disease is one of the most common problems encountered by general surgeons and gastroenterologists. The term refers to complications that arise from colonic diverticulosis including lower gastrointestinal hemorrhage, inflammation, pain, abscess formation, fistula, strictures, perforation and death (1). It is an important cause of morbidity and a significant economic burden (1,2). In 2004, 312,000 admissions and 1.5 million days of inpatient care per year in the United States were due to diverticular disease, at a cost of more than \$US2.6 billion $(3,4)$. A Canadian study (5) estimated that 133,875 admissions for diverticular disease occurred in the province of Ontario between 1998 and 2001. In the present article, we review the epidemiology of diverticular disease and highlight changing trends in its demographics in North America and worldwide. We also outline the current recommendations for the medical and surgical management of diverticular disease.

\section{EPIDEMIOLOGY}

The incidence of diverticular disease has increased over the past century $(2,5,6)$. Autopsy studies from the early part of the 20th century reported colonic diverticula rates of $2 \%$ to $10 \%(6)$. This has increased dramatically over the years. More recent data (5) suggest that up to $50 \%$ of individuals older than 60 years of age have colonic diverticula, with $10 \%$ to $25 \%$ developing complications such as diverticulitis. Hospitalizations for diverticular disease have also been on the rise. According to an American study evaluating hospitalization rates between 1998 and 2005 (2), rates of admission for diverticular disease increased by $26 \%$ during the eight-year study period. Similar trends have been observed in Canadian and European data over the same time period $(5,7)$.

Diverticular disease has traditionally been believed to be a disease affecting the elderly (8). The prevalence of diverticular disease is as high as $65 \%$ by 85 years of age and estimated to be as low as $5 \%$ in those 40 years of age or younger (8). However, more recent literature has

\section{L'épidémiologie et la prise en charge de la maladie diverticulaire}

La maladie diverticulaire du côlon est l'une des pathologies les plus prévalentes de la société occidentale et des principales causes de consultations ambulatoires et d'hospitalisations. On croyait qu'elle touchait surtout les personnes âgées, mais son incidence est en croissance auprès des personnes de moins de 40 ans. La maladie diverticulaire se manifeste surtout sous forme de diverticulite sans complication, et la pierre angulaire du traitement est l'antibiothérapie et le repos intestinal. La colite segmentaire associée aux diverticules partage des caractéristiques histopathologiques avec les maladies inflammatoires de l'intestin et peut profiter d'un traitement aux 5-aminosalicylates. Une prise en charge chirurgicale peut s'imposer en présence de diverticulite récurrente ou de l'une de ses complications, y compris un abcès péridiverticulaire, une perforation, une fistulisation et des sténoses ou des obstructions.

reported an increase in the incidence of diverticular disease among younger patients. For example, a large review of the Nationwide Inpatient Sample (NIS) of 267,000 admissions for acute diverticulitis between 1998 and 2005 (2) showed that the average age of patients decreased over the study period from 64.6 to 61.8 years. Incidence rates increased most dramatically among groups 18 to 44 , and 45 to 64 years of age (incidence per 1000 population: 0.151 to 0.251 , and 0.659 to 0.777 , respectively). In contrast, incidence remained stable over the study period in persons between 65 and 74 years of age, and actually decreased in persons 75 years of age or older. Moreover, a very high incidence of diverticular disease in young patients was reported in a review of 238 patients admitted with diverticulitis to the surgical service at the Medical Center Hospital in San Antonio, Texas (USA) between 1981 and 1990 (9). In this review, 26\% of patients were 40 years of age or younger. These patients had a more aggressive form of disease, requiring more surgical intervention than older patients, and they exhibited a five-fold increase in the risk of complications, such as fistula, compared with their older counterparts. Given the presumption of the low incidence of diverticular disease in young patients, nearly one-half of these patients were often misdiagnosed at presentation - most commonly with appendicitis.

Sex differences among patients with diverticular disease have also been noted throughout the literature, with more recent data showing a change in sex demographics. For example, early reports (10) suggested a higher incidence of diverticular disease among men. A review of all patients admitted to Massachusetts General Hospital (Massachusetts, USA) between 1964 and 1973 (1) showed no difference between sexes (1). However, more recent data have shown that although diverticular disease is still more common among men 50 years or younger, the incidence among women predominates in older age groups $(5,7,9)$. The ratio of men to women with diverticulitis among 61 patients admitted to the Medical Center Hospital in San Antonio who were younger than 40 years of age was 2:1, while women were

${ }^{1}$ Division of Gastroenterology, Mount Sinai Hospital, Faculty of Medicine, University of Toronto, Toronto, Ontario; ${ }^{2}$ Johns Hopkins University School of Medicine, Baltimore, Maryland, USA

Correspondence: Dr Geoffrey C Nguyen, Division of Gastroenterology, Mount Sinai Hospital, 437-600 University Avenue, Toronto, Ontario M5G 1 X5.

Telephone 416-586-4800 ext 2819, fax 416-586-5971, e-mail geoff.nguyen@utoronto.ca

Received for publication November 16, 2010. Accepted November 18, 2010 
more frequently admitted in the older age group with a ratio of $1.5: 1$ (9). The rates of hospitalization were higher among men younger than 50 years of age, but higher for women older than 50 years of age in a review of hospital discharges from 1989 to 2000 in England (United Kingdom) (7). This was consisent with the findings of a Canadian study (5) reporting that men had a hospitalization rate for diverticular disease of 45 per 100,000 in the 40- to 49-year age group compared with 38 per 100,000 in the same age group of women. The incidence was 299 per 100,000 in the 80 years and older age group among men, and 436 per 100,000 in the same age group among women. Women had a higher overall admission rate compared with men between 1998 and 2005 in the review of the NIS database (2) mentioned above. Men accounted for $39 \%$ of admissions compared with $60.7 \%$ for women. This pattern was still evident at the end of the study period (female rate of admission 58.9\%; male rate of admission $41.1 \%$ ). Possible hypotheses for these sex differences have included the protective effect of testosterone on preventing weakening of the colonic wall, and the effect of pregnancy and labour and delivery on contributing to weakening of the wall of the colon.

Diverticular disease has long been regarded as a disease of western countries. The highest prevalence of this condition is in the United States, Europe and Australia, where approximately $50 \%$ of the population 60 years of age and older have diverticulosis $(5,6)$. This common occurrence is in contrast to that in the developing world, where countries in Africa and Asia have prevalence rates of less than $0.5 \%$ $(6,11,12)$. The western diet, particularly its deficiency in dietary fibre, has long been implicated as a causative factor for these geographical variations $(6,13-16)$. This hypothesis was supported by a study that compared stool weight and transit time in 1200 individuals in the United Kingdom and rural Uganda (13). The United Kingdom subjects, who were shown to have lower fibre intake, had a transit time of $80 \mathrm{~h}$ and a mean stool weight of $110 \mathrm{~g} /$ day. This was significantly lower than in the Ugandan subjects, who had much shorter transit times $(34 \mathrm{~h})$ and greater mean stool weights $(450 \mathrm{~g} /$ day $)$. The prolonged transit time and small stool volumes were believed to predispose to diverticular disease by increasing intraluminal pressure. Moreover, there is growing evidence that the rates of symptomatic diverticular disease are on the rise because areas in the developing world are becoming increasingly westernized $(14,15)$. For example, the rates of diverticular disease have increased among urban black populations of South Africa compared with rural black populations in the same country (14). The role of dietary fibre deficiency as a contributor to diverticular disease was further supported by a large prospective cohort study of more than 47,000 men who were followed over a fouryear period (16). Dietary fibre intake was found to be inversely associated with the risk of developing diverticular disease, with an RR of 0.58 (95\% CI 0.41 to $0.83 ; \mathrm{P}=0.01$ ).

In addition to the geographical variability in the prevalence of diverticular disease, there is significant variability in the location of diverticula within the colon in different regions of the world. In western countries, it has been well described that diverticulosis is primarily left sided, particularly involving the sigmoid colon $(2,6-8)$. This is in contrast to findings in Asia, where right-sided diverticulosis dominates (17-19). In a review of 615 cases of diverticulosis detected on doublecontrast barium enema examinations between 1975 and 1982 in Tokyo, Japan (17), 70\% were right sided. Similar diverticular distribution has been shown in Hong Kong and Singapore $(18,19)$. The reason for these differences remains unclear. Early hypotheses suggested that left-sided diverticula were acquired, whereas right-sided diverticula were more likely to be true diverticula and, thus, congenital $(20,21)$. However, subsequent studies have shown that, similar to left-sided diverticula, the majority of right-sided diverticula are 'false' and are likely acquired $(18,22)$. In fact, as Asian populations have begun to adopt a more westernized diet, the rates of diverticular disease have been shown to increase to the same extent noted in the west (17). This increase in diverticular disease, however, remains predominantly right sided. Factors other than deficiencies in dietary fibre are likely to play a role in the development of right-sided diverticulosis as demonstrated by studies that show that even with a high-fibre diet, the rates of right-sided disease are high. For example, a study from China (23) reported a diverticulosis rate of $62 \%$ in patients with high-fibre intake (greater than $14 \mathrm{~g} /$ day). More research is needed in this area to better identify potential causative factors.

\section{MANAGEMENT OF DIVERTICULAR DISEASE} Diverticula-associated pain

The clinical spectrum of diverticular disease is variable, ranging from uncomplicated presentations, such as episodic pain or mild diverticulitis, to potentially life-threatening complicated disease such as abscess, perforation or hemorrhage. Episodes of mild nonspecific abdominal pain, often left sided, can sometimes be attributed to diverticular disease (24). This pain usually occurs in the absence of fever or abnormal laboratory investigations, and is accompanied by an unremarkable physical examination. It may be difficult to clearly associate these episodes with the presence of diverticulosis. These patients can often be observed without any intervention. Alternatively, there is some evidence that increasing dietary fibre may improve symptoms. This was reported in a small randomized trial of 18 patients (25) that showed significant improvement in pain and a decreased number of painful episodes in the high-fibre group at three months.

\section{Segmental colitis associated with diverticula}

The clinical entity of segmental colitis associated with diverticula (SCAD) has become increasingly recognized and is characterized by friable mucosa in the region of diverticula, but typically not involving the diverticula itself and never involving the rectum (26). Patients may present with chronic abdominal pain, particularly left sided, with occasional hematochezia. Pathologically, the mucosa can be indistinguishable from inflammatory bowel disease (27). Case reports have suggested that patients with SCAD may progress to develop Crohn's disease or ulcerative colitis, hypothesizing that there is a pathophysiological link (28). Given this finding, some investigators have evaluated the use of 5-aminosalicylates as a therapy (29). In an uncontrolled Italian study (30), 70 of 86 patients treated with mesalamine $2.4 \mathrm{~g} /$ day for 10 days followed by eight weeks of treatment with $1.6 \mathrm{~g} /$ day showed complete resolution of symptoms with no recurrence.

\section{Uncomplicated diverticulitis}

Diverticulitis without any significant complications accounts for more than $75 \%$ of cases $(31,32)$. These patients typically present with left lower quadrant pain, fever and leukocytosis, and the diagnosis is confirmed on computed tomography scan. The mainstay of treatment in these patients with uncomplicated diverticulitis is antibiotics, bowel rest or a clear fluid diet, with pain control as needed (24). Antibiotic therapy should be aimed at the usual enteric bacteria with Gramnegative and anaerobe coverage. Common outpatient regimens include oral ciprofloxacin and metronidazole, or amoxicillin/clavulanate. For hospitalized patients, an intravenous regimen with broad-spectrum coverage should be selected and may include the following: ceftriaxone and metronidazole; monotherapy with beta-lactam/beta-lactamase inhibitor (eg, piperacillin/tazobactam); or meropenem $(33,34)$. The duration of treatment is typically seven to 10 days.

The decision to admit a patient is based on their clinical status at presentation, the absence of high fever, or significant laboratory or radiographic abnormalities (Figure 1) (24). These patients should be reliable and well supported at home, with the ability to return to hospital if their clinical condition worsens. The immunosuppressed patient should be admitted even if the presentation is mild because they may have more subtle signs, and some data suggest that they are less likely to respond to conventional medical therapy (35). Patients with uncomplicated diverticulitis should be followed and be expected to improve two to three days after presentation, at which time, diet can slowly be advanced (24). Failure to improve should prompt repeat imaging to search for complications and undergo surgical consultation 
(36). Approximately $25 \%$ patients will require surgery for nonresolving diverticulitis (37). Four to six weeks following resolution of the first attack of diverticulitis, patients should undergo endoscopic evaluation to characterize the distribution of diverticula and to exclude any other diagnosis such as colorectal cancer (36).

There are limited data regarding strategies to reduce the risk of diverticulitis recurrence. Given the epidemiological associations between deficiencies in fibre and the incidence of diverticulitis described above, some studies have suggested that a high-fibre diet may be an effective prevention strategy $(5,6,12-16)$; however, supportive evidence is limited. One of the few randomized studies to evaluate this strategy involved 58 patients randomly assigned to a diet high in bran crispbread, ispaghula drink or placebo (38). There was no difference in the subsequent development of symptomatic diverticular disease among the three groups, although the high-fibre groups experienced lower rates of constipation. This is in contrast to a small study of 18 patients (25) that showed decreased episodes of diverticulitis at three months in a high-fibre group. Given its potential benefit, the most recent guidelines from the American Society of Colon and Rectal Surgeons (39) advocate the use of a high-fibre diet after resolution of diverticulitis in an attempt to reduce recurrence. A large number of physicians recommend a diet low in nuts and seeds in an effort to reduce the risk of recurrent diverticulitis. In fact, a survey of 373 colorectal surgeons (34) suggested that approximately one-half recommend the avoidance of seeds and nuts. However, a large cohort study of 47,000 male health professionals followed over an 18-year period (40) found no association between a diet high in corn, seeds or nuts, and subsequent risk of developing diverticulitis. Thus, avoidance of seeds and nuts is not supported by the literature and likely has no role in the management of these patients.

\section{Recurrent diverticulitis}

Approximately one-third of patients will experience recurrence of diverticulitis following an initial episode of uncomplicated diverticulitis $(11,12)$. Some of the earlier literature suggested that recurrent diverticulitis typically had a more severe course. Consequently, guidelines in the 1990s and earlier recommended elective sigmoid resection following the second episode of diverticulitis $(11,36)$. However, more recent evidence $(41,42)$ has shown that recurrent diverticulitis does not necessarily follow a more aggressive course. The most recent guidelines released by the American Society of Colon and Rectal Surgeons (39) recommend that the decision to perform a sigmoid resection following an episode, and recovery following a second episode of acute diverticulitis, should be made on a case-by-case basis, taking into consideration the patient's age and comorbidities, as well as the frequency and severity of the attacks. These recommendations are consistent with those from the Society for Surgery of the Alimentary Tract (43). Although there is no consensus on the threshold number of attacks of diverticulitis before surgery is recommended, a decision analysis (44) showed that deferring surgery until the fourth attack decreased mortality by $0.5 \%$ and need for colostomy by $0.7 \%$ compared with operating after the second attack.

\section{Diverticulitis in younger patients}

The optimal management of young patients presenting with uncomplicated diverticulitis is unclear. As mentioned above, some evidence suggests that young patients are more likely to experience a virulent course and are at a higher cumulative risk of recurrence because of their young age $(9,29)$. This has led some experts to recommend surgery for young patients (younger than 50 years of age) after the initial episode of diverticulitis $(9,29)$. For example, in a study of 52 patients younger than 50 years of age admitted with diverticulitis (45), those younger than 40 years of age had a higher rate of complicated disease compared with those older than 40 years of age ( $72 \%$ versus $35 \%$ ), and they were significantly more likely to require immediate surgery $(40 \%$ versus $13 \%$, respectively; $\mathrm{P}=0.04)$. However, the most recent guidelines from the American Society of Colon and Rectal Surgeons (36,39) advocated that the timing for surgery in younger patients with acute diverticulitis be determined on a case-by-case basis.

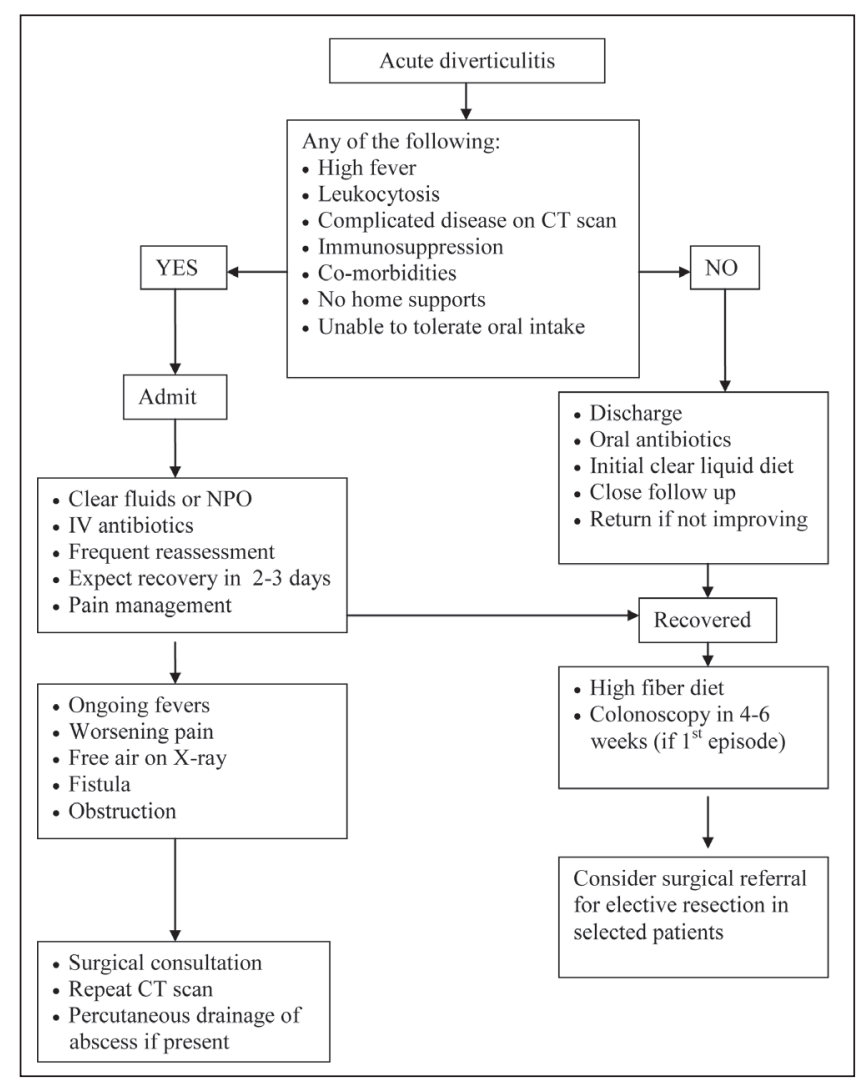

Figure 1) Treatment algorithm for acute diverticulitis. CT Computed tomography; IV Intravenous; NPO Non per oral

The rates of elective surgery following resolution of uncomplicated diverticulitis appear to be increasing (2). A 38\% increase in elective operations was noted in a review of the NIS between 1998 and 2005 (2), with the most significant increase reported in patients 44 years of age or younger ( $73 \%$ increase). These trends have been accompanied by declines in the rates of surgical mortality (1.6\% to $1.0 \%)$ and length of hospital stay ( 5.9 days to 5.3 days). More than $90 \%$ of elective surgeries for diverticulitis resulted in primary anastomoses. The American Society of Colon and Rectal Surgeons has recommended laparoscopic resection whenever possible (39). A Dutch randomized controlled trial (46) that randomly assigned 104 patients to either open or laparoscopic sigmoid resection found that a laparoscopic approach was associated with fewer major complications, less pain and shorter length of hospital stay.

\section{Complicated diverticulitis}

Up to $25 \%$ of patients with acute diverticulitis develop complicated disease (7). This includes abscess formation, fistulas, strictures/obstruction and perforation. Abscess occurs with the perforation of a diverticulum that is usually contained (24). Small abscesses (smaller than $3 \mathrm{~cm}$ ) can often be treated with antibiotics alone (47). Larger abscesses (larger than $4 \mathrm{~cm}$ ) may require computed tomography-guided percutaneous drainage followed by eventual surgery after resolution of the abscess (48). Perforating diverticular disease may also lead to fistula, with the most common locations being colovesicular and colovaginal (49). Fistula complications require surgical management.

Recurrent episodes of diverticulitis can lead to fibrosis and stricturing of the colon, resulting in obstruction most often in the sigmoid colon (24). In managing these strictures, malignancy must first be excluded with surgery indicated if this cannot be definitively achieved (39). Endoscopic dilation can often provide temporary relief of symptoms and allow more access to a stricture to obtain biopsy (50). Moreover, the role of endoscopic stenting in diverticular disease 
is evolving. In a review of 16 patients who underwent stenting for diverticular strictures (51), the procedure was successful in all individuals, allowing subsequent elective resection to be single stage. Similar results have been reported in smaller series (52), all of which support the role of stenting as a temporary measure to enable more elective surgery when the patient's status is more optimized.

Although frank perforation and peritonitis are uncommon complications of diverticulitis, subsequent mortality may be as high as $30 \%$ (53). Thus, prompt recognition of this complication along with early resuscitation, antibiotics and exploratory surgery are cornerstones of management. These patients usually require a Hartmann's procedure, with subsequent closure of colostomy after several months (54). Emergent surgeries for complicated diverticular diseases are commonly performed in multiple stages, usually involving temporary stomas (54). However, even in emergency settings, primary anastomosis may be considered under certain conditions. The Hinchey's classification system is a decision-making tool designed to aid in determining the suitability of primary anastomosis in complicated diverticular disease (55). The classification is characterized by the following four stages: pericolic or mesenteric abscess; walled-off pelvic abscess; generalized purulent peritonitis; and generalized fecal peritonitis. Although somewhat controversial, some studies, including a recent meta-analysis (56), suggest that patients with stage I or II disease can be safely treated with a primary anastomosis, even in the emergent setting. However, the review of the NIS database from 1998 to 2005 (2) reported low rates of primary anastomosis in the acute setting.

\section{SUMMARY}

Diverticular disease is an increasingly common problem that has widely varying presentation ranging from mild outpatient-treated problems to life-threatening perforations requiring emergency surgery. A higher index of suspicion in younger patients is needed because diverticular disease appears to be increasing in incidence among this age group. While it remains primarily a surgically treated disease, medical treatments, such as mesalamine and evolving endoscopic techniques, allow the gastroenterologist to play an important role in managing these patients. It remains a clinical challenge for physicians at many levels including general practioners, emergency room physicians, gastroenterologists and general surgeons.

\section{KEY POINTS}

- A diagnosis of diverticular disease should not be overlooked in younger patients because hospitalization rates in those younger than 40 years of age has significantly increased over the past decade.

- In most cases, uncomplicated acute diverticulitis may be medically managed with antibiotics and bowel rest or clear liquid diet.

- Uncomplicated acute diverticulitis can be managed on an outpatient basis in selected patients who do not have comorbidities (including immunocomprised state) and can tolerate a liquid diet in the absence of fever, significant leukocytosis or evidence of complicated disease on imaging.

- Recurrent diverticulitis or complications of diverticulitis including abscess, perforation, fistulizing disease and strictures/obstruction usually require surgery.

- SCAD has histopathological features similar to inflammatory bowel disease and often responds to 5-aminosalicylate therapy.

\section{REFERENCES}

1. Rodky GV, Welch CE. Changing patterns in the surgical treatment of diverticular disease. Ann Surg 1984;200:466-78.

2. Etzioni DA, Mack TM, Beart RW, et al. Diverticulisis in the United States: 1998-2005: Changing patterns of disease and treatment. Ann Surg 2009;249:210-7.
3. Kozak LJ, DeFrances CJ, Hall MJ. National hospital discharge survery: 2004 annual summary with detailed diagnosis and procedure data. Vital Health Stat 2006;13:1-209.

4. Sandler RS, Everhart JE, Donowitz M, et al. The burden of selected digestive diseases in the United States. Gastroenterology 2002;122:1500-11.

5. Warner E, Crighton EJ, Moineddin R, et al. Fourteen-year study of hospital admissions for diverticular disease in Ontario. Can J Gastroenterol 2007;21:97-9.

6. Painter NS, Burkitt DP. Diverituclar disease of the colon: A deficiency disease of Western civilization. BMJ 1971;2:450-4.

7. Kang JY, Hoare J, Tinto A, et al. Diverticular disease of the colon on the rise: A study of hospital admission in England between 1989/1990 and 1999/2000. Aliment Pharmacol Ther 2003;17:1189-95.

8. Painter, NS, Burkitt, DP. Diverticular disease of the colon, a 20th century problem. Clin Gastroenterol 1975;4:3.

9. Schauer PR, Ramos P, Ghiatas AA, et al. Virulent diveticular disease in young obese men. Am J Surg 1992;164:443-6.

10. Forgey DE. The treatment of diverticulitis of the colon. Am J Proctol 1966;17:278-87.

11. Parks, TG. Natural history of diverticular disease of the colon. Clin Gastroenterol 1975;4:53.

12. Rege RV, Nahrwold DL. Diverticular Disease. Curr Probl Surg 1989;26:133-89.

13. Burkitt DP, Walker AR, Painter NS. Effect of dietary fiber on stool and the transit-times, and its role in the causation of disease. Lancet 1972;2:1408-12.

14. Walker AR, Segal I. Epidemology of noninfective intestinal disease in various ethnic groups in South Africa. Isr J Med Sci 1979;15:309-13.

15. Ogunbiyi OA. Diverticular disease of the colon in Ibadan, Nigeria. Afr J Med Med Sci 1989;18:241-4.

16. Aldoori WH, Giovannucci EL, Rimm EB et al. A prospective study of diet and the risk of symptomatic diverticular disease in men. Am J Clin Nutr 1994;60:757-64.

17. Sugihara K, Muto T, Morioka Y et al. Diverticular disease of the colon in Japan: A review of 615 cases. Dis Colon Rectum 1984;27:531-7.

18. Markham NI, Li AK. Diverticulitis of the right colon - experience from Hong Kong. Gut 1992;33:547-9.

19. Ngoi SS, Chia J, Goh MY et al. Surgical management of right colon diverticulitis. Dis Colon Rectum 1992;35:799-802.

20. Wagner ED, Zollinger RW. Diverticulitis of the cecum and ascending colon. Arch Surg 1961;83:124-31.

21. Evans A. Developmental enterogenous cysts and diverticula. Br J Surg 1929;17:34-83.

22. Hughes LE. Postmortem survery of diverticular disease of the colon. Gut 1969;10:336-51.

23. Pan G, Liu T, Chen $M$ et al. Diverticular disease of the colon in China. Chin Med J 1984;97:391-4.

24. Stollman N, Raskin JB. Diverticular disease of the colon. Lancet 2004;363:631-9.

25. Brodribb AJ. Treatment of symptomatic diverticular disease with a high-fiber diet. Lancet 1977;1:664-6.

26. Gore S, Shepherd NA, Wilkinson SP. Endoscopic crescentic fold disease of the sigmoid colon: The clinical and histolopatholical spectrum of a distinctive endoscopic appearance. Int J Colorectal Dis 1992;7:76-81.

27. Jani N, Finkelstein S, Blumberg D, et al. Segmental colitis associated with diverticulosis. Dig Dis Sci 2002;47:1175-81.

28. Pereira MC. Diverticular disease-associated colitis: Progression to severe chronic ulcerative colitis after sigmoid surgery. Gastrointest Endosc 1998;48:520-3.

29. Sheth AA, Longo W, Floch M. Diverticular disease and Diverticulitis. Am J Gastrol 2008;103:1550-6.

30. Brandimarte G, Tursi A. Rifaximin plus mesalazine followed by mesalazine alone is highly effective in obtaining remission of symptomatic uncomplicated diverticular disease. Med Sci Monit 2004;10:170-3.

31. Detry R, Jamez J, Kartheuser A, et al. Acute localized diverticulitis: Optimum management requires accurate staging. Int J Colorectal Dis 1992;7:38-42.

32. Thompson WG, Patel DG. Clinical picture of diverticular disease of the colon. Clin Gastroenterol 1986;15:903-16. 
33. Chow AW. Appendicitis and diverticulitis. In: Hoeprich PD, Jordan MC, Ronald AR, eds. Infectious Diseases: A Treatise of Infectious Processes. Philadelphia: JB Lippincott, 1994:878-81.

34. Schechter S, Mulvey J, and Eisenstat TE. Management of uncomplicated acute diverticulitis: Results of a survey. Dis Colon Rectum 1999;42:470-5.

35. Perkins JD, Shield CF, Change FC, et al. Acute diverticulitis: Comparison of treatment in immunocompromised patient. Arch Surg 1991;126:855-8.

36. Roberts P, Abel M, Rosen L, et al. The standards task force of the American Society of Colon and Rectal Surgeons. Practice parameters for sigmoid diverticulitis: Supporting documentation. Dis Colon Rectum 1995;38:126-32.

37. Roberts PL, Veidenheimer MC. Current management of diverticulitis. Adv Surg 1994:27:189-208.

38. Ornstein MH, Littlewood ER, Baird IM, et al. Are fibre supplements really necessary in diverticular disease of the colon? A controlled clinical trial. Br Med J (Clin Res Ed) 1981;282:1353-6.

39. Rafferty J, Shellito P, Hyman NH, et al. Practice parateters for sigmoid diverticulitis. Dis Colon Rectum 2006;49:939-44.

40. Strate LL, Liu YL, Syngal S, et al. Nut, corn, and popcorn consumption and the incidence of diverticular disease. JAMA 2008;300:907-14.

41. Chapman JR, Dozois EJ, Wolff BG, et al. Diverticulitis: A progressive disease? Do multiple recurrences predict less favourable outcomes? Ann Surg 2006;243:876-80.

42. Wolff B, Chapman J. Complicated diverticulitis: It is not yet time to rethink the rules! Ann Surg 2006;243:708.

43. The Society of Surgery for the Alimentary Tract. SSAT Patient Care Guidelines" Surgical Treatment of Diverticulitis. < http://www. ssat.com/cgi-bin/divert.cgi> (Accessed on April 27, 2011).

44. Salem L, Veenstra DL, Sullivan SD, et al. The timing of elective colectomy in diverticulitis: A decision analysis. J Am Coll Surg 2004;199:904-12.

45. Pautrat K, Bretagnol F, Huten N, de Calan L. Acute diverticulitis in very young patients: A frequent surgical management. Dis Colon Rectum 2007;50:472-7.
46. Klarenbeek BR, Veenhof AA, Bergamaschi R, et al. Laparoscopic sigmoid resection for diverticulitis decreases major morbidity rates: A randomized control trial: Short-term results of the Sigma Trial. Ann Surg 2009;249:39-44.

47. Ambrosetti P, Robert K, Witzig JA, et al. Incidence, outcome, and proposed management of isolate abscesses complicating acute left-sided colonic diverticulitis: A prospective study of 140 patients. Dis Colon Rectum 1992;35:1072-6.

48. Schechter S, Eisenstat TE, Oliver GC, et al. Computerized tomographic-scan guided drainage of intra-abdominal abscesses: Preoperative and postoperative modalities in colon and rectal surgery. Dis Colon Rectum 1994;37:984-8.

49. Woods RJ, Lavery IC, Fazio VW, et al. Internal distulas in diverticular disease. Dis Colon Rectum 1988;31:591-6.

50. Mantem H, Zara J, Rakin J. Balloon dilatation of rectosigmoid stricutres: Transendoscopic approach. Gastrointest Endosc 1986;32:164

51. Small AJ, Young-Fadok TM, Baron TH. Expandable metal stent placement for benign colorectal obstruction: outcomes for 23 cases. Surg Endosc 2008;22:454-62.

52. Keranen I, Lepisto A, Udd M, et al. Outcome of patients after endoluminal stent placement for benign colorectal obstruction. Scand J Gastroenterol 2010;45:725-31.

53. Nagorney DM, Adson MA, Pemberton JH. Sigmoid diverticulitis with perforation and generalized peritonitis. Dis Colon Rectum 1985;28:71-5.

54. Constantinides VA, Tekkis PP, Athanasiou T, et al. Primary resection with anastomosis vs. Hartmann's procedure in nonelective surgery for acute colonic diverticulitis: A systematic review. Dis Colon Rectum 2006;49:966-81.

55. Hinchey EJ, Schaal PG, Richards GK. Treatment of perforated diverticular disease of the colon. Adv Surg 1978;12:85-109.

56. Salem L, Flum DR. Primary anastomosis or Hartmann's procedure for patients with diverticular peritonitis? A systematic review. Dis Colon Rectum 2004:47:1953-64. 


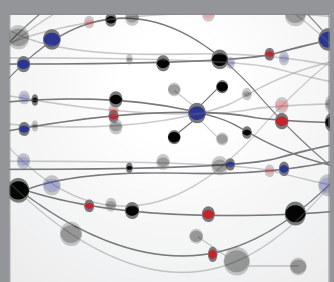

The Scientific World Journal
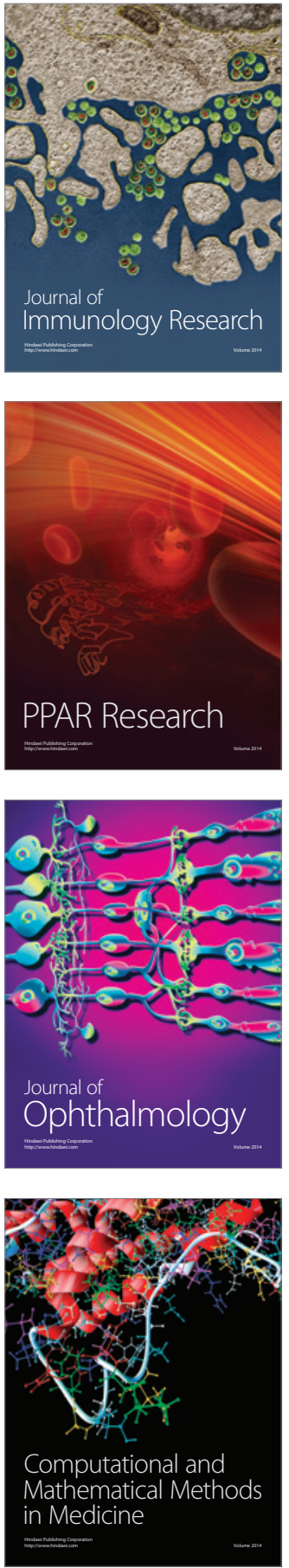

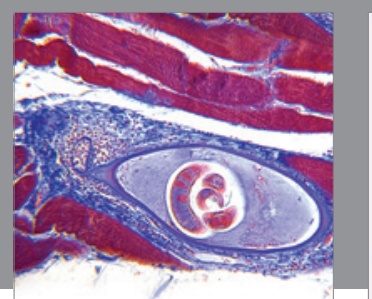

Gastroenterology Research and Practice

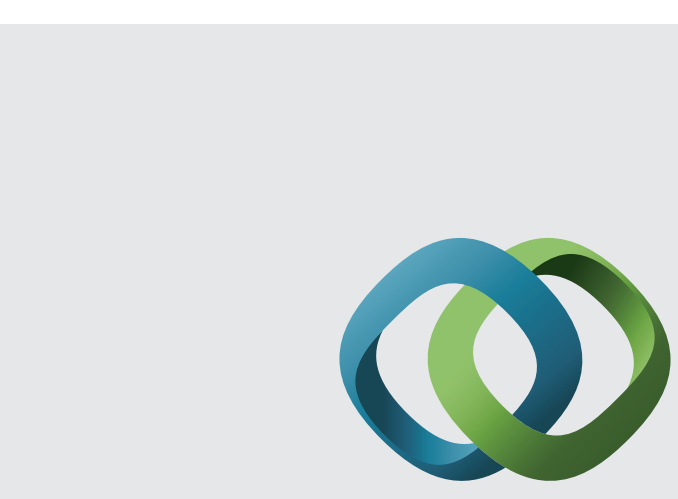

\section{Hindawi}

Submit your manuscripts at

http://www.hindawi.com
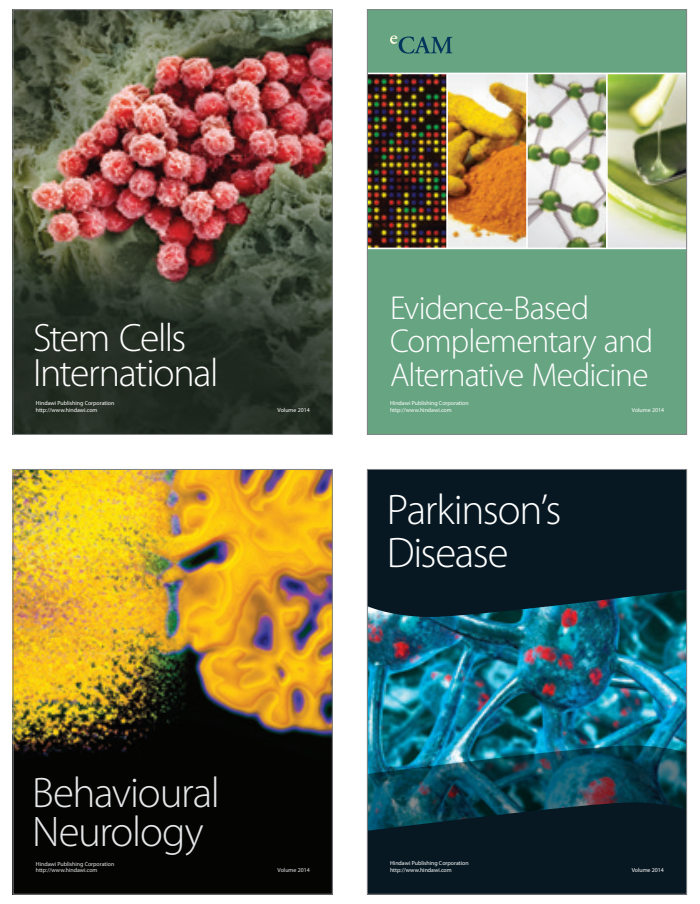
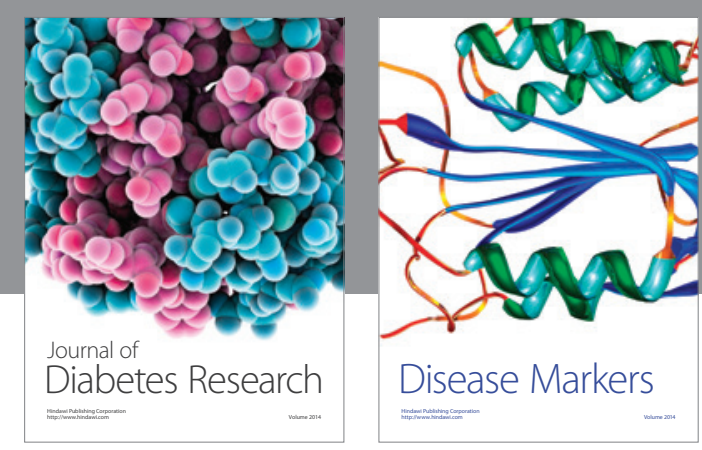

Disease Markers
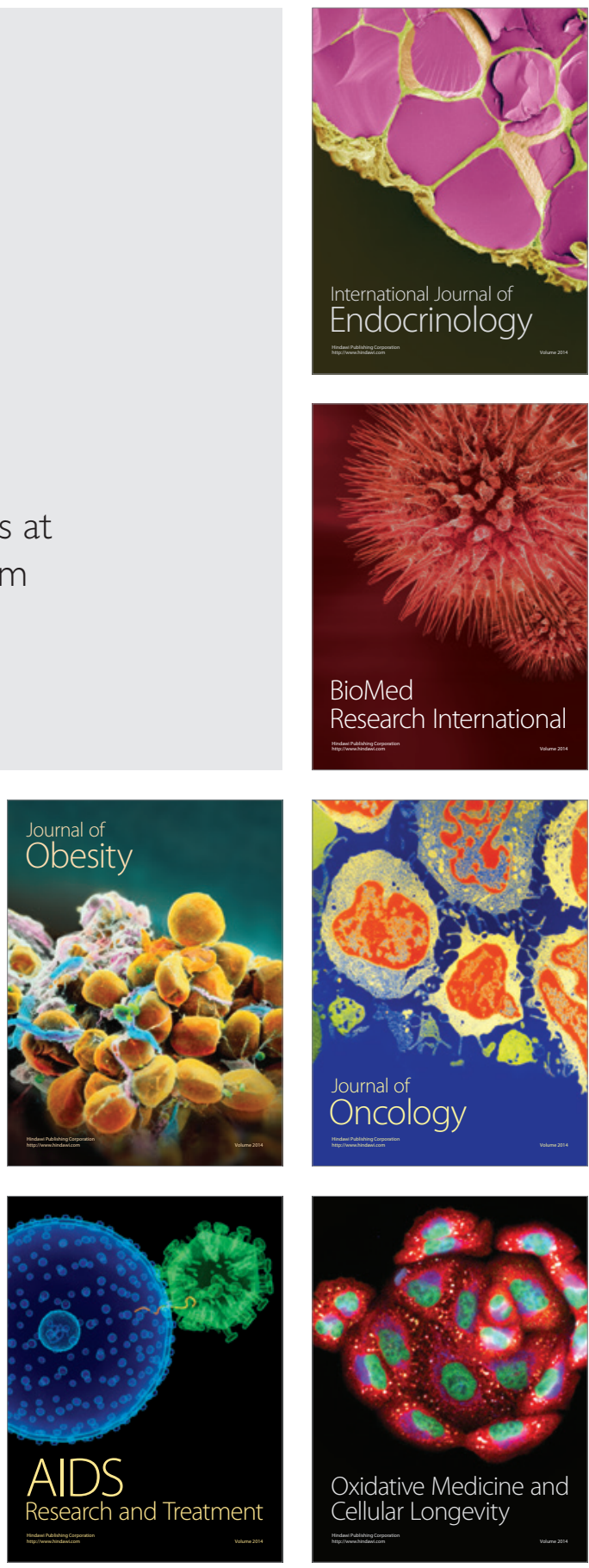